\title{
A Study on Cultural Connotation of Animal Words in English and Chinese
}

\author{
Wang Yinggang , Cui Xuena \\ Qinhuangdao Institute of Technology ,Qinhuangdao City ,Hebei Province ,China \\ Yinggang066100@163.com
}

Keywords: culture connotation; animal words; connotation correspondence

\begin{abstract}
Every animal word has its own cultural connotation. Obviously, different animal words, even the same animal words, have the same, similar or contrary cultural connotations in different languages. So it brings misunderstanding and cultural shock in intercultural communication. This paper tries to discuss the cultural connotations of animal words in English and Chinese from the following aspects: cultural connotation correspondence, cultural connotation non-correspondence and cultural connotation zero both in English and Chinese. Through the comparison, it is clear to conclude that this discrepancy of languages is the epitome of the differences of English and Chinese cultures. Therefore, if people want to communicate with English-speaking people confidently and successfully, people firstly have to enrich their knowledge of different cultures, make clear the differences and understand the cultural connotations of these animal words.
\end{abstract}

\section{Introduction}

Animals are good friends of human beings. Along with the development of human society and the interaction of these two species, human beings keep close relations with animals and the close relationship profoundly influence human beings' emotions, values, religions, languages, etc. Every animal word not only has its own denotation but also has cultural connotation. Obviously, some animal words have the same or similar cultural connotations in different languages, however, different cultural environment more possibly make people associate an animal word, even the same animal word, with quite different images or emotions. In other words, animal words are given special cultural connotations for the different social backgrounds and national conventions. So it brings misunderstandings and cultural shocks, which are all obstacles we should overcome in intercultural communication.

As we all know, English has become one of the most open languages around the world. Since it was born, it has never stopped its self-development and meanwhile assimilated other cultural essence from different countries. As the result, it can be sure that the animal words in English language have rich cultural implications. And Chinese, as one of the oldest languages in the world, has evolved over 5000 years. The animal words in Chinese have their own specific cultural connotations as well. For these reasons, it is worthwhile to make a good comparison of animal words between English and Chinese both for the English language learners and Chinese language learners. It can help them get a better comprehension of the intercultural communication as well.

In recent years, many linguists, as Chen Dezhang, Hu Wenzhong, have paid much attention to intercultural communication. They devote much to pragmatics, comparison of languages and cultures between English and Chinese. They also published many papers on the comparison of animal words in the two languages. But there are only a few papers on systematic comparison of cultural connotations of animal words in English and Chinese.

This paper focuses on the correspondence of cultural connotation of animal words in both Chinese and English. The paper is divided into four parts. The first part gives a definition of culture connotation. The following three parts make a detailed comparison of cultural connotations of animal words in these two languages from three aspects: cultural connotation correspondence, connotation non-correspondence and cultural connotation zero. Then it is safe to conclude that to be 
aware of different cultural connotations of animal words in the two countries will help us understand each other's language and culture much better.

\section{Definition of Cultural Connotation}

The human perception of the world is universally similar but the detailed understanding of the world would be different from society to society because of the differences in surroundings, life style, values, beliefs and history. Thus cultural connotation of words covers social conventions, the outlook of values and national appreciations and so on.

To know cultural connotation, we should know the definition of connotation first: The Longman Modern English Dictionary (4th edition) gives connotation the following definition: "the implication of a word, apart from its primary meaning." Webster's New Collegiate Dictionary (8th edition) defines the word connotation as: "the suggesting of a meaning by a word apart from the thing it explicitly names or describes." These two definitions show that the connotation of a word is different from its denotation-its explicit meaning. It is essential that we know not only the denotation of words, but also the connotations. Cultural connotation refers to the general meaning including connotative meaning and cultural meaning carried in different cultural circumstance, it includes the meaning added and the amplified meaning under special social and cultural background, and also includes the emotions and attitudes of some particular cultural colony. 1 People should carefully apply the phrases and terms of animal words whenever communicating with foreigners or doing translation. Sometimes it is a hard task to convey the cultural connotation of animal words.

\section{Cultural Connotation Correspondence of Animal Words}

Same cultural connotation of same animal words. Thanks to the similar ecological environment, animal has marked characteristics whether Chinese or English speaking people have something in common on the attitude towards them even use them in comparison to describe the special properties of people or things. So people in the two cultures tried to study animal words from the animal's basic properties, which offer them the same or similar association and cultural connotation. There are similar sayings in the two languages such as "as meek as a lamb” , "as happy as a lark" , "make a monkey out of somebody" is like the Chinese saying .

Swan stands for holiness and purity in English, meanwhile, in Chinese ,the saying "a toad wants to eat a swan" refers to fantasy impractically. The ugliness of toad is used to lay emphasis on the holiness of swan. Swans dance in China originated from a legend in which a beautiful girl jumped into the water in order to fight against feudal marriage. Finally, she became a pretty swan. In English, the swan in "All your swans are geese." refers to nice wish. English speaking people use bug to refer to someone who is partial to somebody or something, such as "a camera bug”, "a football bug”, "a bug at sports”.

In China , bug has a similar usage, for example, "a lazy bug”means a lazy person; “a confused bug” refers to an unwise person; “ a silverfish” refers to someone who embezzle national or others' properties.

These animal words with both the same denotative meaning and connotative meaning proved that they reflect the common characters of the two cultures in some aspects. To most people, there are some similarities in the national environment and their living conditions. So many animal words possess the same connotation, even in two different cultures. There are many other examples to show the same animal has the same cultural connotation in both languages, such as:

Wolf as cruel as a wolf

Pig eat like a pig, make a pig of oneself

Bee as busy as a bee

Ass make an ass of oneself

Dog live a dog's life 
Same cultural connotation of different animal words. In English and Chinese, different animal words can have the same or similar connotation. That means people from two cultures respectively use different animal words to express the same meaning though the animal words are different. These words show that people in different cultures understand the objects by the same means and the phenomenon is related to history and aesthetic appreciations to some extent. In Chinese, we usually use mouse to describe a person who is timid. In English, they describe a timid person as chicken, rabbit, and pigeon. For example, as timid as a rabbit; Don't be scared, chicken; He is pigeon-livered. In English, they may use this idiom like a cat on hot bricks when they want to describe a vexatious person. In Chinese, we will use another animal word: ant. For example, like an ant on a hot pan.

Horse stands for strong, robust, and sturdy in English culture. Meanwhile, we Chinese use bull or ox to stands for the same meaning with horse. When English people describe a strong man, they describe him as strong as a horse. In Chinese, we say: as strong as an ox. In English, if someone likes boasting, they say he talks horse. But in Chinese, we use "blowing an ox".

Here are some other examples of translations containing different images of animals in Chinese and in English which express the same cultural connotation.

A snipe fight with a clam but a fisherman got them together two dog fight for a bone and third runs away with it.

Love a house love the bird on it love me love my dog

Kill two birds with an arrow kill two birds with one stone

Kill the chicken that lays the golden egg kill the goose that lays the golden egg

one should not twist the tiger's pat one should not twist the lion's tail

Fox in a tiger's hide donkey in a lion's hide

These above examples proved that different animal words can stand for the same connotation. Different cultural connotations result in different expressions.

\section{Cultural Connotation Non-correspondence of Animal Words}

In more possible cases, the same referential image of an animal word has obviously different, conflicted even opposite cultural connotations in two cultures. This common phenomenon in language is worth attention. Thanks for different cultural environments and different aesthetic appreciations, Chinese and English- speaking people endow animals with different imaginations and offer animal word richer cultural connotations to animal. In the following paragraphs, the differences of cultural connotation of animal words in English and Chinese are discussed from two aspects: Commendation in English but derogation in Chinese and Commendation in Chinese but derogation in English.

Commendation in English but derogation in Chinese. First, let us take dog as a typical example. The word dog is favorable in its connotation in the English language because most English-speaking people think dogs are people's faithful friends which stand for bravery, loyalty and cleverness. We often hear idioms like these: a lucky dog; Every dog has its day means every person will some day succeed or become fortunate; To help a lame dog over the stile means to help someone in difficulty; An old dog barks not in vain means the old people are experienced. These dogs refer to lucky people and don't have a derogatory sense. However, the images of dog are not that lucky in China though Chinese people think dogs are man's faithful friends. In most Chinese phrases, dog is associated with some derogatory connotation. For example, people are short in dogs' eyes (look down upon sb./sth. ), etc.

In addition, sometimes the images of animals have to be dropped for translation, as it is hard to find any animals that have a similar connotation. For example, It is raining cats and dog; My dogs are killing me; under the black dog; dog someone's footsteps, etc. These metaphorical expressions have to be translated correctly in order to convey the right information. Otherwise they will cause communication barriers.

Apart from the above examples, there are many other animals, such as cricket, cuckoo, bat, petrel and mouse, having favorable meanings in English but having derogatory meaning in Chinese. 
In a word, it is safe to state that the English-speaking people have very different associations with most animals from the Chinese. This is a reflection of different cultures.

Commendation in Chinese but derogation in English. People believe that the different cultural connotation between English dragon and Chinese "long" has been known all around the world. Besides, the phoenix also has a favorable fame in China but derogate in western countries. Phoenix is the king of all the birds in Chinese legend. It is believed that phoenix is the symbol of peacefulness and brings people good luck. In ancient times, it was used to describe a person with virtue. A phoenix flies out of a mountain means that a person with special ability comes from a remote village. However, in English, it is said that phoenix lived in Sahara for about 500 years. It would build a nest covered with spice before burning itself into ashes from which a new phoenix was born. Therefore, phoenix, in English, stands for regeneration. For example, Religion, like a phoenix, has been resurrected from the ashes of the war.

In Chinese, magpie is an auspicious bird. It is said that its voice brings good news. What's more, its voice is the forecast of fine weather. It is proved that magpie can bring us good luck, whereas in English, it refers to gab, tragedy and doom. So, in English culture, magpie is a kind of animal that everyone hates. Most of time it has a derogatory sense. For example, she is a magpie of woman; she kept muttering like a magpie. Furthermore, it is suggested that people in English- speaking countries feel disgusted towards its voice which stands for chaos, disorder. For example, a magpie collection; to magpie together, etc.

In English fish has a derogatory sense, associated with bad people and things. There are phrases like a poor fish; a loose fish; fish in the air and so on. On the contrary, every year in China when people get together to celebrate the Spring Festival, they always make dishes with fish which stand for wealth . Because fish sounds the same as surplus which means having a surplus.

\section{Conclusion}

Through the comparison of cultural connotation of animal words between English and Chinese, it is clear to conclude that animal word is not only a sign of animal but also has profoundly cultural connotation in different cultures. This discrepancy of language is the epitome of the difference of two different cultures--English and Chinese. Therefore, if people want to have a good grasp of animal words, they must try their best to understand the connotations of these words, especially the cultural connotations. It is also necessary to enrich our knowledge of different cultures as much as possible and make clear the differences of cultures between English and Chinese in order to understand correctly cultural connotation of words. Only deeply acquainting themselves with the cultural convention and living customs, can people communicate with English-speaking people confidently and successfully.

\section{References}

[1]Anderson, A. \&Lynch, A.J.Listening.London: oxford University Press, 1988.

[2]Benedict Ruth. Patterns of culture. New York: Houghton Mifflin company, Boston, 1935.

[3]Bloomfield L. Language [M].Beijing: Foreign Language Teaching and Research Press, 2002.

[4]Bochner, S. (ed.) Cultures in Contact: Studies in Cross-cultural Interaction [M]. Oxford: Pergamon Press, 1982.

[5]Brown Gillian, et al.Language and Understanding [M].Shanghai: Shanghai Foreign Language Education Press, 2000. 